\title{
Estimation of snow cover distribution in Beas basin, Indian Himalaya using satellite data and ground measurements
}

\author{
H S Negi ${ }^{1, *}$, A V Kulkarni ${ }^{2}$ and B S Semwal ${ }^{3}$ \\ ${ }^{1}$ Snow 8 Avalanche Study Establishment, Chandigarh 160 036, India. \\ ${ }^{2}$ Space Applications Centre, Ahmedabad, 380 015, India. \\ ${ }^{3}$ H N B Garhwal University, Srinagar Garhwal, 246 174, India. \\ *e-mail: negi_hs@yahoo.com
}

In the present paper, a methodology has been developed for the mapping of snow cover in Beas basin, Indian Himalaya using AWiFS (IRS-P6) satellite data. The complexities in the mapping of snow cover in the study area are snow under vegetation, contaminated snow and patchy snow. To overcome these problems, field measurements using spectroradiometer were carried out and reflectance/snow indices trend were studied. By evaluation and validation of different topographic correction models, it was observed that, the normalized difference snow index (NDSI) values remain constant with the variations in slope and aspect and thus NDSI can take care of topography effects. Different snow cover mapping methods using snow indices are compared to find the suitable mapping technique. The proposed methodology for snow cover mapping uses the NDSI (estimated using planetary reflectance), NIR band reflectance and forest/vegetation cover information. The satellite estimated snow or non-snow pixel information using proposed methodology was validated with the snow cover information collected at three observatory locations and it was found that the algorithm classify all the sample points correctly, once that pixel is cloud free. The snow cover distribution was estimated using one year (2004-05) cloud free satellite data and good correlation was observed between increase/decrease areal extent of seasonal snow cover and ground observed fresh snowfall and standing snow data.

\section{Introduction}

The highly reflective nature of snow combined with its large surface coverage, makes snow an important component of the Earth's radiation balance, as snow can cover more than $40 \%$ of the Earth's land surface during the Northern Hemisphere winter (Robinson and Kukla 1985). The dates of occurrence and disappearance and the duration of snow cover are important factors for human activities, particularly in the Northern Hemisphere. Outside of polar region, the Himalayan range is covered with snow mainly due to high elevated mountain ranges. In addition, large areas of Himalaya are also covered by seasonal snow fall during winter time, which starts ablating in the spring, therefore areal extent of snow cover changes significantly during winter and spring. During spring and summer, this can affect stream flow of the rivers originating from different basins of the Higher Himalaya. It exerts an influence on hydropower generation system, water management, strategic planning and many other developmental activities, which contribute to national economy. In addition, snow cover can cause formation of avalanches, which in turn strongly affect the safety of human lives and property. Therefore, mapping of areal extent is an important parameter for various hydrological, climatological, and snow-hazard applications.

It is difficult to obtain snow cover information on repetitive basis from vast snow covered areas of Himalaya, which is at high altitude,

Keywords. Snow cover monitoring; NDSI; AWiFS; reflectance; topographic corrections. 
rugged and inaccessible; using ground conventional techniques (manned snow-meteorological observatories). Satellite remote sensing has proven useful tool for real-time, year-round and large spatial coverage for monitoring and process studies over vast, rugged and remote areas (Konig et al 2001). The different medium resolution satellite sensors, e.g., Landsat MSS and TM have been used for the mapping of snow cover area over drainage basins (Dozier et al 1981; Rango and Martinec 1982; Dozier 1984, 1989). For operational snow cover monitoring using these medium resolution sensors, there are certain issues, e.g., suitable temporal resolution, spectral resolution, radiometric resolution and swath. Until recently most of the satellite sensors such as Landsat-MSS and TM, IRS-LISS which unfortunately have become saturated for snow due to its high reflectance in most of their spectral regions. Now, availability of data from new sensors such as AWiFS on-board IRS-P6 has not only helped us in overcoming the saturation problem due to their high radiometric resolutions but also facilitated the effective monitoring of large snow covered areas as a result of high temporal resolution and wide swath coverage (Kulkarni et al 2006).

Initially, the mapping process was largely based on the conventional techniques such as manual delineation of snow cover boundaries, segmentation of ratio images and hard or crisp classification. Other analysis techniques such as visual, hybrid (visual and supervised classification) have also been used to estimate the areal extent of snow cover (Kulkarni and Rathore 2003). However, a major difficulty in snow cover monitoring using above techniques is mountain shadow and confusing signature of snow and cloud in the visible and near-infrared region. Because of the above-mentioned reasons, reflectance ratio/index approaches were introduced as they can remove the effects of some sensor radiometric errors and random changes in scene irradiance due to changing effects in the atmosphere and topographical changes across the scene (Slater 1980). Negi et al (2009a, b) have discussed the detailed spectroradiometer field experiments for different types of snow and to understand the impact of different snow characteristics (grain size variation, moisture, contamination, snow depth, mixed objects snow reflectance, etc.) on the reflectance and following snow indices.

\subsection{Normalized difference snow index (NDSI)}

The NDSI is analogous to the normalized difference vegetation index (NDVI) (Tucker 1979, 1986; Townshend and Tucker 1984) and useful for the identification of snow and ice, and for discriminating snow/ice from most cumulus clouds. NDSI method is generally used for snow cover mapping using satellite data (Hall et al 1995, 2002, Kulkarni et al 2002b, 2006; Gupta et al 2005; Negi et al 2008). NDSI uses the high and low reflectance of snow in visible (Green) and shortwave infrared (SWIR) region respectively and it can also delineate and map the snow in mountain shadows (Kulkarni et al 2002b). Additionally, the reflectance of clouds remains high in SWIR band, thus NDSI allows in discriminating some clouds and snow. NDSI is defined by following relation and it ranges from -1 to +1 .

$$
\mathrm{NDSI}=\frac{\text { Green }-\mathrm{SWIR}}{\text { Green }+ \text { SWIR }}
$$

where Green and SWIR are the reflectances of the Green and shortwave infrared bands respectively.

A threshold value for NDSI of 0.4 is defined for the pixels that are approximately $50 \%$ or greater covered by snow from the imageries of different sensors (Xiao et al 2001). However, identification of snow covered areas using NDSI is difficult if snow covered areas are mixed with vegetation (Hall et al 1998). To handle the mixed area, the threshold value of NDSI was lowered from 0.4 to 0.1 (Klein et al 1998), by referring to the NDVI.

\subsection{S3 index}

To identify snow under vegetation, normalized snow index S3 was also proposed (Saito and Yamazaki 1999):

$$
\mathrm{S} 3=\frac{\mathrm{NIR}(\mathrm{Red}-\mathrm{SWIR})}{(\mathrm{NIR}+\mathrm{Red})(\mathrm{NIR}+\mathrm{SWIR})}
$$

where NIR, Red and SWIR are the reflectances of the near-infrared, red (visible) and shortwave infrared bands respectively. S3 uses the reflectance characteristics of snow and vegetation to reduce the errors caused by snow covered areas mixed with vegetation. Shimamura et al (2006), found the threshold value of S3 index for snow cover area greater than 0.18 and for the snow under vegetation it is distributed from 0.05 to 0.18 .

In the present paper, the snow reflectance/ indices are evaluated and validated for the mapping of snow cover using AWiFS satellite data, for a complex terrain, which contains snow under vegetation, contaminated snow and patchy snow during the winter period. A methodology is developed for the mapping of snow cover and validated with the ground observed data. 


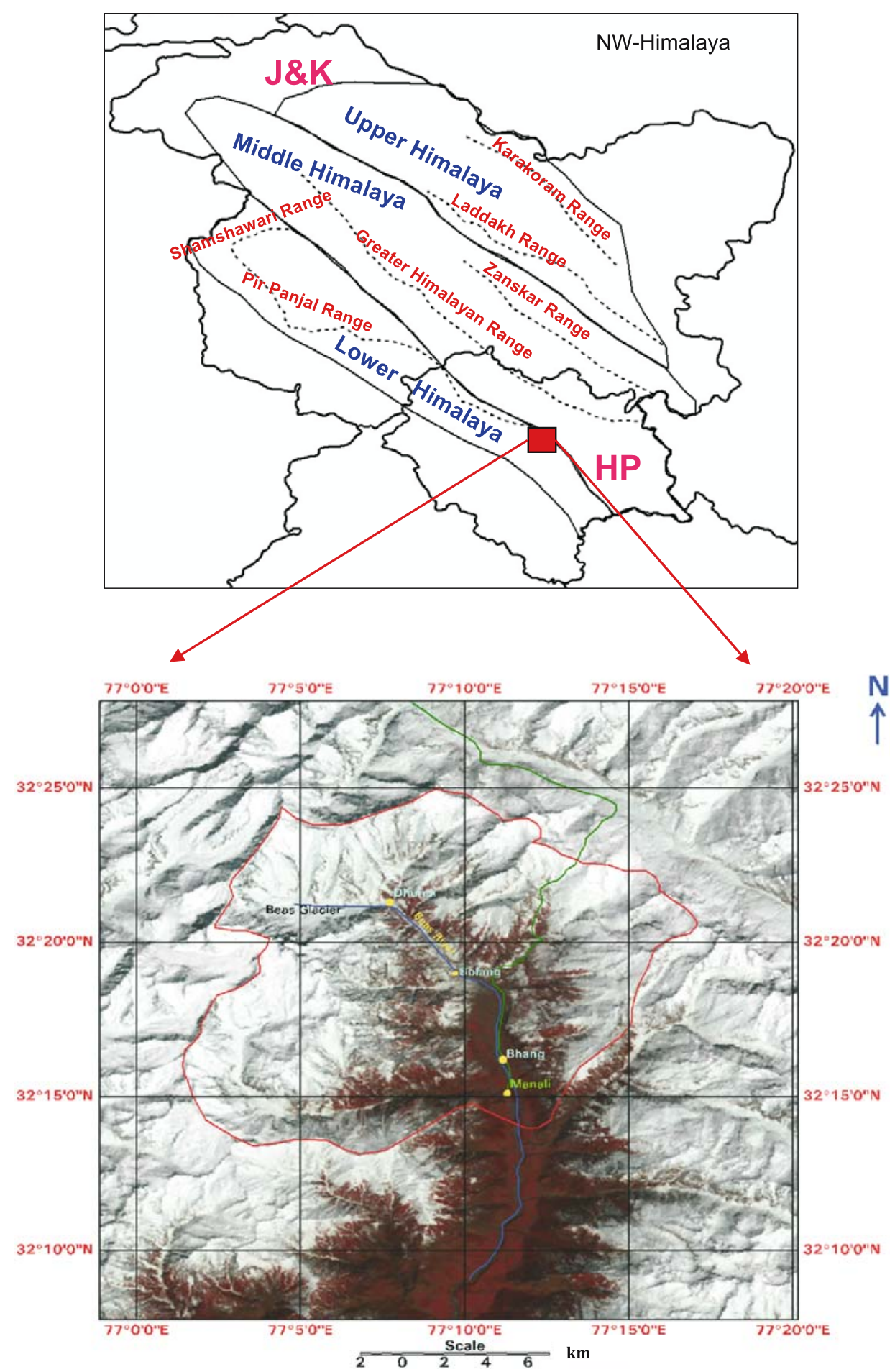

Figure 1. Study area showing Beas basin and SASE observatories locations; AWiFS imagery bands (B2:B3:B4).

\section{Study area}

In the present study, Beas basin of Himachal Pardesh (Indian Himalaya) is selected as a study area, from where the Beas river originates (figure 1). Thus being a catchment area of a river it is important to monitor the snow cover as it has lot of applications. Climatically, this area falls in the lower Himalayan zone (Sharma and Ganju 2000) and characterized by moderate temperature as mean minimum temperature $-1.6^{\circ} \mathrm{C}$, lowest minimum $-12^{\circ} \mathrm{C}$ and mean maximum $7.7^{\circ} \mathrm{C}$ during winter (November to April) and high precipitation as mean standing snow $165 \mathrm{~cm}$ and mean cumulative snowfall $363 \mathrm{~cm}$ in the month of January (Singh and Ganju 2006). Due to moderate temperatures, the winter period remains short and the snow cover changes into 


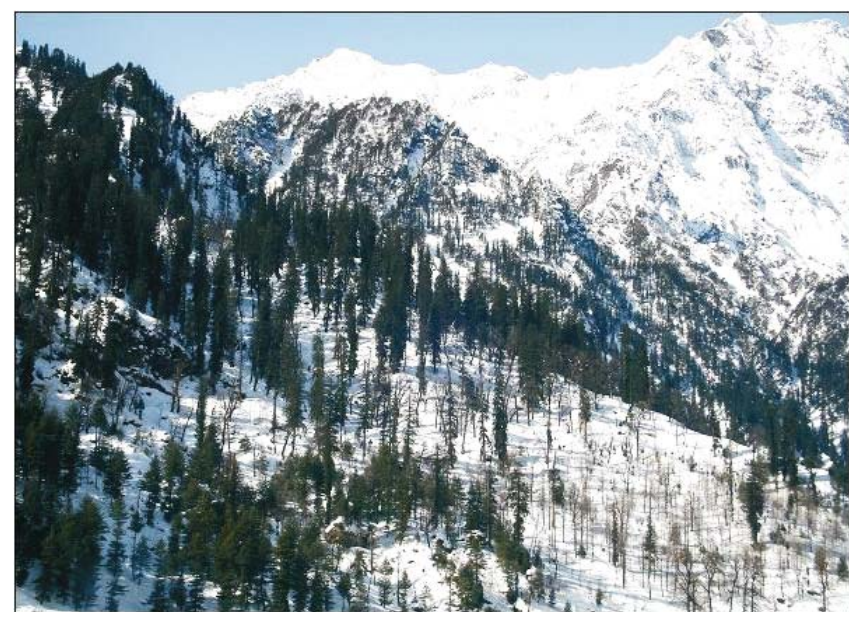

Figure 2. View of snow under vegetation of the study area during winter.

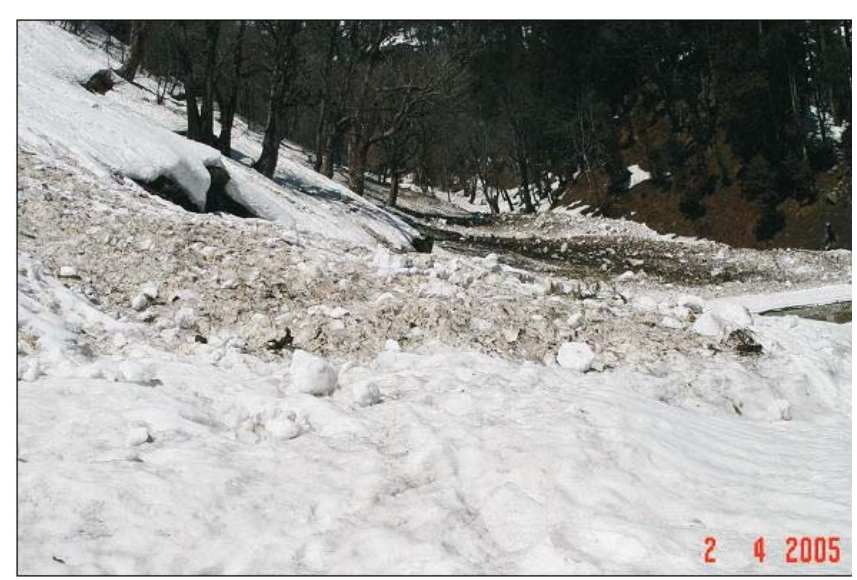

Figure 3. Contaminated avalanche debris along the Manali-Dhundi road.

$0^{\circ} \mathrm{C}$ isothermal. The average altitude of this zone is between 2000 and $4000 \mathrm{~m}$. However, middle Himalayan zone is characterized by cold temperature, mostly glaciated and altitude varies from 3500 to $5300 \mathrm{~m}$ and the upper Himalayan zone is extremely cold, receives dry snow and highly glaciated which is somewhat close to continental snow conditions, and altitude more than $5000 \mathrm{~m}$. As the study area receives high precipitation and significant changes in the snow characteristics due to moderate temperature, it also receives lot of avalanche activities along Manali-Leh highway, which is very important highway to the population of Ladhak, as it connects Ladhak division with rest of the country.

In addition to catchment areas of Beas river, snow cover distribution was carried out because the areal extent of snow significantly changes in summer due to melting. This provides ample opportunity to validate snow indices under different melting conditions. This area also covers vegetation (pine trees), therefore it become complex to monitor the snow cover under trees and vegetation mixed area with snow cover using satellite data (figure 2). During melting season the snow become contaminated and also full depth contaminated avalanches trigger in this region (figure 3), which necessitates the study of contaminated snow for the generation of snow cover monitoring algorithm. In addition, this region can be accessible during winter time and field collected snow-meteorological data are available from three observatories locations. The total area of the basin is approximately $347 \mathrm{~km}^{2}$.

\section{Data used}

\subsection{Ground measurements}

The detailed spectroradiometer survey was conducted in study area to understand the impact of different snow characteristics on snow reflectance and snow indices (Negi et al 2009a, b). The spectral signatures of different ambient objects, such as vegetation, grass, barren land, soil, water body, etc., were also collected in the study area. Spectral reflectance was collected using a portable field spectroradiometer Field Spec Pro FR (Analytical Spectral Devices 1999), in the wavelength range $350-2500 \mathrm{~nm}$.

\subsection{Ground observatory data}

Snow and Avalanche Study Establishment (SASE) has its own snow-meteorological observatories at Bhang (2039 m), Solang (2480 m) and Dhundi (3050) in Beas basin area. For field validation of satellite data, ground observed snow meteorological parameters, viz., fresh snowfall, standing snow, snow surface temperature, minimum temperature, maximum temperature, etc., collected at above observation stations are used in the present study.

\subsection{Digital data}

The AWiFS sensor data have been used for snow cover analysis of year 2004-05, due to its high receptivity, large swath, high saturation radiances and has the better spatial resolution at 5-day repeat cycle (Kulkarni et al 2006). The detailed parameters of AWiFS sensor is given in table 1 . Total of 19 AWiFS cloud free imagery, out of 48 scenes from September 2004 to June 2005 are selected for the snow cover mapping. Survey of India (SoI) map sheets at 1:50,000 scale are used for the generation of digital elevation model (DEM) and vector data of study area, i.e., locations, road and basin boundary. 
Table 1. Major performance parameters of AWiFS camera (source: Kulkarni et al 2006).

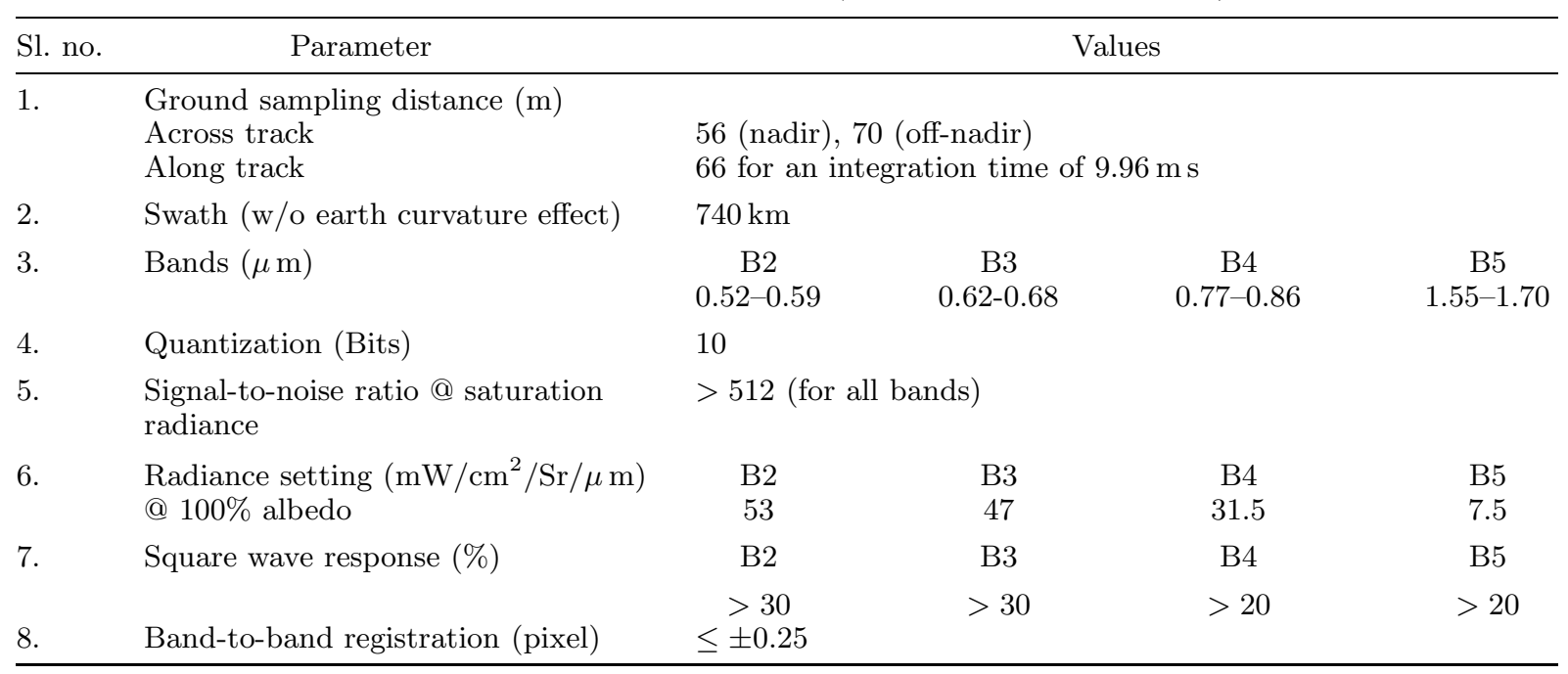

\section{Methodology}

\subsection{Satellite data processing}

The ERDAS Imagine software, was used for the pre-processing of satellite data. DEM generated from mapsheet was used for the ortho-rectification of satellite data, as Himalayan terrain is very rugged; it requires ortho-corrected imagery with good accuracy to extract meaningful snow cover information.

\subsubsection{DN to spectral radiances}

Satellite sensors measure the upwelling radiance above the earth's atmosphere, and the received signals from various targets are represented on an image in terms of digital numbers (DN). Spectral radiance from pixel in each band, denoted by $L_{\lambda}$ $\left(\mathrm{mWcm}^{-2} \mathrm{Sr}^{-1} \mu \mathrm{m}^{-1}\right)$, is proportional to its digital number (DN) and computed using following formula (Markham and Barker 1986):

$$
L_{\lambda}=\operatorname{Gain}_{\lambda} \times \mathrm{DN}_{\lambda}+\operatorname{Bias}_{\lambda},
$$

where, $\operatorname{Gain}_{\lambda}$ is the calibration gain coefficient of the sensor $\left(\mathrm{mW} \mathrm{cm}{ }^{-2} \mathrm{sr}^{-1} \mu \mathrm{m}^{-1}\right.$ counts $\left.^{-1}\right), \mathrm{DN}_{\lambda}$ is the digital number of a pixel in a particular band (counts), and Bias ${ }_{\lambda}$ is the calibration offset of the sensor band $\left(\mathrm{mW} \mathrm{cm}{ }^{-2} \mathrm{sr}^{-1} \mu \mathrm{m}^{-1}\right)$.

Equation (3) can be expressed as:

$$
L_{\lambda}=\frac{\left(L_{\max \lambda}-L_{\min \lambda}\right)\left(\mathrm{DN}_{\lambda}-Q \operatorname{cal}_{\min \lambda}\right)}{\left(Q \operatorname{cal}_{\max \lambda}-Q \operatorname{cal}_{\min \lambda}\right)}+L_{\min \lambda}
$$

where $L_{\min \lambda}$ is the spectral radiance for each band at $\mathrm{DN}_{\lambda}=0, L_{\max \lambda}$ is the spectral radiance for each band at $\mathrm{DN}_{\lambda}=\mathrm{DN}_{\max \lambda}, Q \operatorname{cal}_{\min \lambda}$ is the minimum value of $\mathrm{DN}_{\lambda}=\mathrm{DN}_{\min \lambda}=0$, and $Q \operatorname{cal}_{\max \lambda}$ is the $\mathrm{DN}_{\max \lambda}$ (i.e., 1023 for AWiFS).

The $L_{\max \lambda}$ for each band of AWiFS is given in table 1 (Sl. no. 6); thus radiance values were calculated using above information.

All the algorithms and equations were generated in ERDAS Imagine spatial modeler environment for the processing of satellite data.

\subsubsection{Atmospheric correction}

In the present study, the dark object subtraction (DOS) model has been used to correct the atmospheric effect from the image. This correction can be performed in multispectral data by observing the radiance recorded over target areas of essentially zero values such as deep clear water in the NIR region of the spectrum (Chavez 1989, 1996; Moran et al 1992; Song et al 2001). Therefore, any signal observed over such an area represents the path radiance and these values can be subtracted from all the pixels in all the bands. The improper dark pixel selection will sometimes result in DOS values being either over or underestimated, this may not be valid depending on the uniformity of the atmosphere over a scene. The DOS method uses the relative diffusion model expressed as a power law of the form $(\lambda)^{-n}$, depending upon atmospheric conditions to predict the haze values to be subtracted for each spectral band (Chavez 1988), where the value of $n$ is $4,2,0.7$ and 0.5 for very clear, clear/moderate, hazy and very hazy, respectively. The atmospheric coefficient constant based on the scattering coefficient values are estimated for each AWiFS band. 
In the present study, the radiances from water body (lakes) present in the full scene of AWiFS were collected and this radiance values $\left(\right.$ Radiance $_{d}$ ) were subtracted as given by following equation to correct every band for atmospheric correction.

$$
L_{i \lambda}=\text { Radiance }_{i \lambda}-\left(K_{i \lambda} \times \text { Radiance }_{d}\right),
$$

where $L_{i \lambda}$ is the Atmospherically corrected radiance of the pixel, $K_{i \lambda}$ is atmospheric coefficient constant (multiplication factor) for each band, and Radiance $_{d}$ is radiance of the dark object (water body) in the NIR band.

\subsubsection{Topographic corrections}

Himalayan region is very rugged and undulating therefore in order to understand the effect of topography on various snow parameters, different topographic correction models have been attempted, as there is no topographic correction method generally applicable to all applications. In the present study three commonly used methods (Lambertian cosine correction, Minnaert correction and C-correction) were evaluated, to see how successfully they can be applied on AWiFS imagery of 26 February 2005 of study area, as the field spectral data were also measured on the same day, nearly at the time of satellite pass.

The cosine correction, assumes that incident radiation is reflected in all directions equally, i.e., Lambertian reflectance characteristics and considers only direct irradiance although the proportion of diffuse skylight can be relatively high, particularly in weakly illuminated areas. The following cosine correction equation was used for topographic corrections (Teillet et al 1982):

$$
L_{H}=L_{T} \times\left(\frac{\cos (z)}{\cos (i)}\right),
$$

where $L_{H}$ is the radiance for horizontal surface; $L_{T}$ is the radiance observed over the inclined terrain; $\cos (z)$ and $\cos (i)$ are solar zenith angle and local incidence angle to the terrain surface (i.e., the angle between the surface normal and the solar beam) respectively, and calculated for a pixel by the formula (Kasten 1962 for $\cos (z)$ and Smith et al 1980 for $\cos (i))$ :

$$
\cos (z)=\cos (\varphi) \cos (\delta) \cos (t)+\sin (\varphi) \sin (\delta),
$$

where $\varphi$ is geographic latitude of the observer; $\delta$ is declination of the sun and $t$ is local hour angle of the sun (unit of all are in degree):

$$
\cos (i)=\cos (z) \cos (e)+\sin (z) \sin (e) \cos (\Omega-A s),
$$

where $e$ is slope inclination; $\Omega$ is solar azimuth; and $A s$ is surface aspect of the slope angle.

The Minnaert correction is an extension of the Lambertian model employing the Minnaert constant, $k$, which varies between 0 and 1 (Minnaert 1941). The constant $k$ is empirically determined for the actual surface, and its purpose is to handle non-Lambertian surfaces (anisotropic reflectors). The following Minnaert equation was used for topographic corrections:

$$
L_{H}=L_{T} \times\left(\frac{\cos (z)}{\cos (i)}\right)^{k} .
$$

Since the Minnaert constant is wavelengthdependent, separate constants need to be derived for each band. The term $k$ is equal to the slope of the following regression equation:

$$
\begin{aligned}
\log (L \times \cos (e))= & \log L_{n}+k \\
& \times \log (\cos (i) \times \cos (e)) .
\end{aligned}
$$

where $L_{n}$ is radiance when $i=0$. The equation (10), is linear form in $y=m x+c$; and regression value of $k$ calculated using slope of the equation; where $x=\log (\cos (i) \cos (e))$; $y=\log (L \cos (e))$ and $c=\log L_{n}$.

The C-correction is based on a similar semiempirical approach as the Minnaert correction. The C-correction assumes a statistical linear relationship between the $\cos (i)$ and the radiance. The parameter $C$ is introduced as an additive term to counterbalance and prevent possible overcorrection which often occurs when using a solely Lambertian approach such as the cosine correction. The $C$ factor derived from the regression of $L=m \times \cos (i)+b$; as the quotient of the gradient and intercept of the linear regression equation, so that $C=b / m$. Terrain corrected reflectance $L_{H}$ is then derived using the following equation:

$$
L_{H}=L_{T} \times \frac{(\cos (z)+C)}{(\cos (i)+C)} .
$$

The statistical analysis was carried out to test the accuracy of the topographic corrections, using above different models for the entire scene as well as on both sunny and shady slopes of the 
images. For the field validation, the spectral data was collected at latitude $32^{\circ} 16^{\prime} 21^{\prime \prime} \mathrm{N}$; longitude $77^{\circ} 10^{\prime} 58^{\prime \prime} \mathrm{E}$; altitude $1953 \mathrm{~m}$. It is difficult to verify the field observed radiance accurately with the same latitude and longitude using satellite estimated value because the point of experiment lie in a habitat area, which may give some variations in the radiance values of medium spatial resolution pixel of $56 \mathrm{~m}$. Therefore, the satellite estimated radiances using different topographic models were verified with the field results in the neighbourhood snow pixel, approximately at same altitude, on the image at location (latitude $32^{\circ} 16^{\prime} 20^{\prime \prime} \mathrm{N}$; longitude $77^{\circ} 10^{\prime} 49^{\prime \prime} \mathrm{E}$; altitude $1951 \mathrm{~m})$.

\subsubsection{Estimation of reflectance}

By considering the snow cover as a Lambertian surface, the reflectance of each AWiFS band was derived directly from the satellite data using atmospheric corrected radiances, without any terrain correction as given below (Dozier 1984):

$$
R_{i \lambda}=\frac{\Pi \cdot L_{\lambda} \cdot d^{2}}{E \operatorname{sun}_{\lambda} \cdot \cos z},
$$

where $R_{i \lambda}$ is the reflectance of a pixel in a particular band, $L_{\lambda}$ is corrected spectral radiance from pixel in each band $\left(\mathrm{mW} / \mathrm{cm}^{2} / \mathrm{sr} / \mu \mathrm{m}\right), d$ is earth-sun distance in astronomical units (AU), $E \operatorname{sun}_{\lambda}$ is mean solar exoatmosheric spectral irradiance $\left(\mathrm{mW} / \mathrm{cm}^{2} / \mu \mathrm{m}\right)$, and $z$ is solar zenith angle (degree).

The values of the mean solar exoatmosheric spectral irradiance $\left(E \operatorname{sun}_{\lambda}\right)$ for AWiFS bands $2-5$ are $185.111,158.376,110.251$ and $24.042 \mathrm{mWcm}^{-2} \mu \mathrm{m}^{-1}$, respectively. The spectral reflectance was further estimated for topographic corrected radiances (cosine, Minnaert and $\mathrm{C}$ corrections, given by equations 6,9 and 11 , respectively) as well as with the original ortho-corrected radiances, using equation (12) and compared with field measured reflectance values.

\subsubsection{Estimation of NDSI and S3 index}

In the Himalayan region, during winter time the classification techniques like supervised, unsupervised, etc., are difficult to apply due to mountain shadow and cloud cover (Kulkarni 2000a). This problem can be partially solved if the technique based upon the normalized difference snow index (NDSI) is properly developed. The NDSI is estimated for AWiFS sensor data using the following relationship (Kulkarni et al 2006):

$$
\text { NDSI }(\text { AWiFS })=\frac{\text { Green (B2) }- \text { SWIR (B5) }}{\text { Green (B2) }+ \text { SWIR (B5) }} \text {. }
$$

Similarly, the S3 snow index proposed by Saito and Yamazaki (1999), was estimated for AWiFS sensor data using the following relationship:

$$
\mathrm{S} 3(\mathrm{AWiFS})=\frac{\mathrm{B} 4(\mathrm{~B} 3-\mathrm{B} 5)}{(\mathrm{B} 4+\mathrm{B} 3)(\mathrm{B} 4+\mathrm{B} 5)} .
$$

The snow cover area was delineated using the threshold value of S3 index greater than 0.18 and for the snow under vegetation it is distributed from 0.05 to 0.18 (Shimamura et al 2006).

\subsection{Snow cover mapping}

\subsubsection{Snow cover mapping using different techniques}

To find the suitable snow mapping technique for the study area, different index based techniques were attempted as NDSI using DN values, NDSI using planetary reflectance, NDSI using cosine corrections and S3 index. Five scenes of AWiFS on monthly basis (i.e., 2 December of 2004 and 19 January, 26 February, 13 March, 30 April of 2005) were selected for the different snow cover mapping techniques. The threshold value of NDSI $\geq 0.4$ (Kulkarni et al 2006) and similarly the threshold value of $\mathrm{S} 3 \geq 0.18$ (Saito and Yamazaki 1999) was used for snow cover mapping. The comparative analysis of snow cover area (\%) using AWiFS data was carried out for different snow cover mapping techniques.

\subsubsection{Snow cover distribution in Beas basin using AWiFS data}

Based on the results of different snow cover mapping techniques, the proposed algorithm for the snow cover mapping of the study area is shown in figure 4 . To measure the snow under vegetation, the vegetation area was identified in the study area using high resolution LISS-IV (IRS-P6) multispectral imagery of pre-winter (i.e., 29 October 2004). The supervised classification was carried out to identify the vegetation area and five classes were generated including shadow. The contingency matrix (error matrix) was generated for the supervised classified LISS-IV image and the kappa coefficient was estimated. 


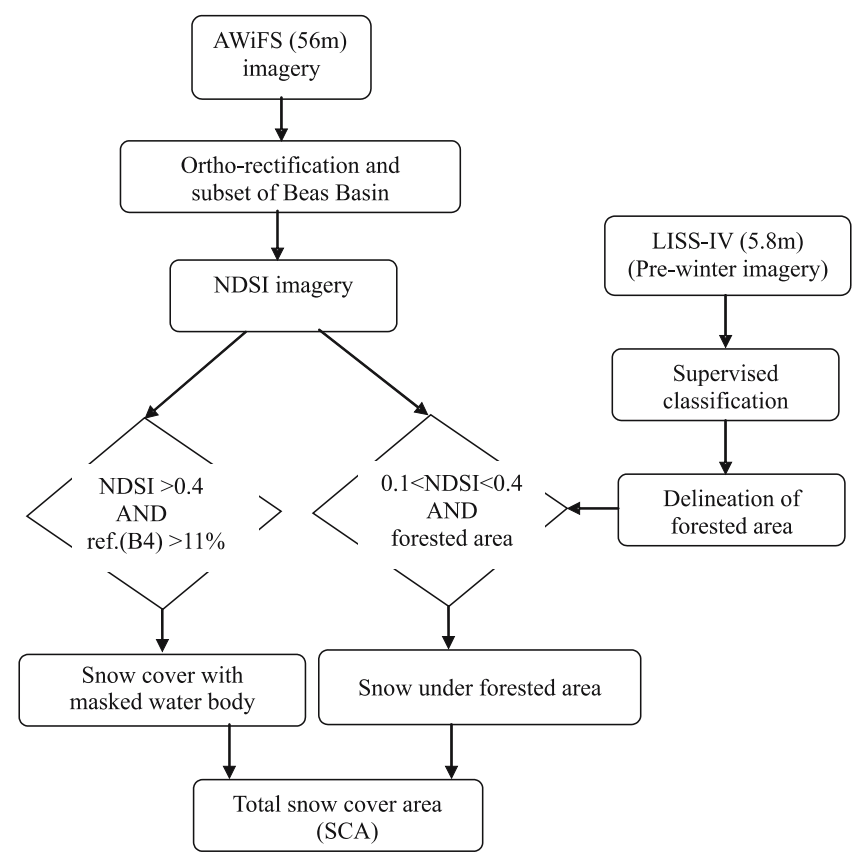

Figure 4. Flow chart of methodology for snow cover mapping.

The NDSI images were generated from AWiFS images, and water body pixels merging with snow, were masked using the B4 (NIR) reflectance threshold value $>11 \%$. This value was selected using lakes present in the full AWiFS scenes. For mapping of snow under vegetation, for which the NDSI threshold value may reduce from 0.4 to 0.1 , a criteria has been applied that if the pixel's value lies in this NDSI range and pixel falls in a vegetation area (identified using LISS-IV), it was classified as snow under forest area or snow mixed with vegetation area, as this value may also reduce in case of contaminated and patchy snow. If the vegetation is absent and the NDSI value lies between 0.1 and 0.4 , then the pixel may be patchy or contaminated snow (Negi et al 2009a). Finally, total snow cover area was calculated, which take care of vegetation/forest mix and merging of water body with snow.

The pointwise validation, i.e., with respect to snow meteorological observatory locations, data was carried out for snow or non-snow pixel, and increase/decrease in snow cover areal extent was validated with fresh snowfall, standing snow and temperature data.

\section{Results and discussions}

\subsection{Results of radiance and reflectance models}

Topographic corrections were carried out using different methods on AWiFS scene of 26 February 2005. The estimated value of $\mathrm{C}$ and Minnaert constant were found to be $0.709,0.685,0.695$, 0.735 and $0.579,0.570,0.571,0.572$ respectively in band 2 to band 5 . In order to test the accuracy of the topographic corrections statistically, mean value and standard deviations of spectral radiances are compared for the entire study area. Table 2 shows that for cosine correction, there is significant increase of the mean value together with decrease in the standard deviations only for two bands (band 3 and band 4) in the entire image, when compared to the original image. If the correction is successful, the values of standard deviations should decrease. Again, the correction is successful, if the mean value of radiances on the shady side increases while those on the sunny side should decrease. From table 3, it can be observed that the cosine corrected mean radiance values on the shady side become significantly higher than that on the sunny side, which shows the image is overcorrected and this supports and confirms the observation described by Teillet et al (1982), Meyer et al (1993) and Ekstrand (1996). However, it should be noted that the problem of cast-shadow, where the incident angle $i>90^{\circ}$, is not handled in this correction method and remains to be uncorrected. Using $\mathrm{C}$ and Minnaert corrections, the mean radiance value increases and the standard deviation decreases in three bands (bands 2 to 4 ) for the entire scene (table 2). Further, table 3 shows that for C-corrections, the mean values on the shady slope and sunny slope are comparable and better than the Minnaert corrections. Thus C-correction can be found as the best topographic correction method among the above three corrections as it normalizes all slopes and aspect with respect to maximum illumination. Further, it can be observed from table 4 that $\mathrm{C}$-corrected radiances are more close to the original image and field measured radiances.

The field validation of snow reflectance was carried out nearby the field experiment location, with not much change in altitude, as it has been found in the study area that, some time the snowfall occurred at higher elevations but not at the lower. It can be inferred from table 5 that satellite estimated snow reflectance without topography corrections are more comparable with field results in all the satellite bands of AWiFS, for that particular location. The inclusion of topography in the estimation of reflectance using different methods show underestimated reflectance values. It is inferred using topographic consideration results that present available models are needed to be refined further for snow applications in Himalayan terrain. The reliability of the topographic corrections may be analysed with the results of reflectance values using different slope and aspect separately. 
Table 2. Means and standard deviations for the entire study area.

\begin{tabular}{|c|c|c|c|c|c|c|c|c|}
\hline \multirow[b]{2}{*}{ Band no. } & \multicolumn{2}{|c|}{ Original image } & \multicolumn{2}{|c|}{ Cosine-corrected } & \multicolumn{2}{|c|}{ C-corrected } & \multicolumn{2}{|c|}{ Minnaert-corrected } \\
\hline & $\mu$ & $\sigma$ & $\mu$ & $\sigma$ & $\mu$ & $\sigma$ & $\mu$ & $\sigma$ \\
\hline Band 2 & 29.69 & 11.69 & 33.68 & 11.95 & 32.01 & 11.23 & 33.03 & 11.48 \\
\hline Band 3 & 24.88 & 10.25 & 27.65 & 9.71 & 26.60 & 9.5 & 27.33 & 9.56 \\
\hline Band 4 & 16.94 & 6.93 & 18.86 & 6.64 & 18.10 & 6.46 & 18.63 & 6.47 \\
\hline Band 5 & 0.51 & 0.24 & 0.59 & 0.31 & 0.59 & 0.45 & 0.58 & 0.34 \\
\hline
\end{tabular}

Table 3. Mean radiance value from AWiFS image on different side of slopes.

\begin{tabular}{llcccr}
\hline & & \multicolumn{2}{c}{ Mean radiance from AWiFS image (26 February 2005) } \\
\cline { 3 - 5 } & AWiFS & $\begin{array}{c}\text { Original } \\
\text { Ortho-corrected }\end{array}$ & $\begin{array}{c}\text { Cosine- } \\
\text { corrected }\end{array}$ & $\begin{array}{c}\text { Minnaert- } \\
\text { corrected }\end{array}$ \\
\hline Slope facing & Band no. & 34.39 & 30.74 & 32.32 & 32.26 \\
to the Sun & Band 2 & 29.07 & 25.87 & 27.23 & 27.20 \\
& Band 4 & 19.85 & 17.67 & 18.60 & 18.57 \\
Slope facing away & Band 5 & 0.57 & 0.52 & 0.54 & 0.54 \\
from the Sun & Band 2 & 25.34 & 36.79 & 31.39 & 34.22 \\
& Band 3 & 20.99 & 29.57 & 25.76 & 27.76 \\
& Band 4 & 14.22 & 20.11 & 17.42 & 18.86 \\
& Band 5 & 0.44 & 0.67 & 0.54 & 0.64 \\
\hline
\end{tabular}

Table 4. Comparison of snow radiances results obtained from satellite data of AWiFS (26 February 2005) using different topographic models with field measured radiances using spectroradiometer.

\begin{tabular}{|c|c|c|c|c|c|}
\hline \multirow[b]{2}{*}{ Band no. } & \multicolumn{4}{|c|}{ Radiance from AWiFS image (26 February 2005) } & \multirow{2}{*}{$\begin{array}{l}\text { Field measured } \\
\text { spectroradiometer } \\
\text { radiance }\end{array}$} \\
\hline & $\begin{array}{c}\text { Original } \\
\text { Ortho-corrected }\end{array}$ & Cosine-corrected & C-corrected & $\begin{array}{l}\text { Minnaert- } \\
\text { corrected }\end{array}$ & \\
\hline Band 2 & 27.935 & 27.534 & 27.728 & 27.645 & 26.344 \\
\hline Band 3 & 23.621 & 23.282 & 23.443 & 23.376 & 23.802 \\
\hline Band 4 & 15.366 & 15.145 & 15.251 & 15.205 & 16.075 \\
\hline Band 5 & 0.182 & 0.179 & 0.180 & 0.180 & 0.013 \\
\hline Latitude & \multicolumn{4}{|c|}{$32^{\circ} 16^{\prime} 20^{\prime \prime} \mathrm{N}$} & $32^{\circ} 16^{\prime} 21^{\prime \prime} \mathrm{N}$ \\
\hline Longitude & \multicolumn{4}{|c|}{$77^{\circ} 10^{\prime} 49^{\prime \prime} \mathrm{E}$} & $77^{\circ} 10^{\prime} 58^{\prime \prime} \mathrm{E}$ \\
\hline Altitude & \multicolumn{4}{|c|}{$1951 \mathrm{~m}$} & $1953 \mathrm{~m}$ \\
\hline
\end{tabular}

In the above analysis, it was observed that at location 1 , snow is 10 days old; however, at location 2 , snowfall also occurred in between, i.e., on 24 and 20 February 2005 as 2 and $4 \mathrm{~cm}$ respectively; and at location 3 , snowfall also occurred on 25 and 24 February 2005 as 4 and $22 \mathrm{~cm}$ respectively. This shows that location 3 has fresh snow as compared to location 1 on 26 February 2005, and hence the estimated reflectance decreases as we go to lower elevations (table 5), which verifies the aging effect of snow on reflectance (Negi et al 2009b). It was also observed that as the slope increases (from location 1 to location 3); the estimated reflectance using different methods also varies significantly for topographic as well as non-topographic corrections (which is obvious). However, the estimated NDSI values remain the same for reflectance observed without topographic correction and with topographic corrections (table 5). In view of this fact, the topographic corrections are not considered in the present snow cover mapping study, as NDSI technique is used for the mapping of snow cover using AWiFS data.

\subsection{Snow cover mapping}

\subsubsection{Snow cover mapping using different techniques}

To find the suitable, index based technique the snow cover area was estimated (\%) using NDSI (based on DN; planetary reflectance; cosine 
Table 5. Comparison of snow reflectance results obtained from satellite data of AWiFS (26 February 2005) using different topographic models with field measured reflectance using spectroradiometer.

\begin{tabular}{|c|c|c|c|c|c|c|}
\hline \multirow[b]{2}{*}{ Location no. } & \multirow[b]{2}{*}{$\begin{array}{l}\text { AWiFS } \\
\text { band }\end{array}$} & \multicolumn{4}{|c|}{ Reflectance from AWiFS image (26 February 2005) } & \multirow{2}{*}{$\begin{array}{l}\text { Field } \\
\text { measured } \\
\text { spectro- } \\
\text { radiometer } \\
\text { reflectance }\end{array}$} \\
\hline & & $\begin{array}{l}\text { Without } \\
\text { topography } \\
\text { corrected }\end{array}$ & $\begin{array}{l}\text { Cosine- } \\
\text { corrected }\end{array}$ & C-corrected & $\begin{array}{l}\text { Minnaert- } \\
\text { corrected }\end{array}$ & \\
\hline \multirow{5}{*}{$\begin{array}{l}\text { 1. Near Bhang } \\
\text { Lat: } 32^{\circ} 16^{\prime} 20^{\prime \prime} \mathrm{N} \\
\text { Long: } 77^{\circ} 10^{\prime} 49^{\prime \prime} \mathrm{E} \\
\text { Altitude: } 1951 \mathrm{~m} \\
\text { Slope: } 5^{\circ} \\
\text { Aspect: } 56^{\circ}\end{array}$} & Band 2 & 62.501 & 61.352 & 61.907 & 61.844 & 73.174 \\
\hline & Band 3 & 64.834 & 63.642 & 64.207 & 64.152 & 73.936 \\
\hline & Band 4 & 59.030 & 57.945 & 58.463 & 58.408 & 66.628 \\
\hline & Band 5 & 3.145 & 3.087 & 3.115 & 3.111 & 1.377 \\
\hline & NDSI & 0.904 & 0.904 & 0.904 & 0.904 & 0.963 \\
\hline 2. Near Solang & Band 2 & 68.098 & 69.742 & 68.931 & 69.029 & \multirow{5}{*}{$\begin{array}{l}\text { No field } \\
\text { collected } \\
\text { data of } \\
\text { same date }\end{array}$} \\
\hline Lat: $32^{\circ} 19^{\prime} 02^{\prime \prime} \mathrm{N}$ & Band 3 & 67.282 & 68.907 & 68.119 & 68.203 & \\
\hline Long: $77^{\circ} 09^{\prime} 26^{\prime \prime} \mathrm{E}$ & Band 4 & 65.961 & 67.554 & 66.776 & 66.866 & \\
\hline Altitude: $2455 \mathrm{~m}$ & Band 5 & 3.386 & 3.468 & 3.427 & 3.433 & \\
\hline $\begin{array}{l}\text { Slope: } 15^{\circ} \\
\text { Aspect: } 114^{\circ}\end{array}$ & NDSI & 0.905 & 0.905 & 0.905 & 0.905 & \\
\hline 3. Near Dhundi & Band 2 & 87.688 & 70.705 & 78.076 & 77.576 & \multirow{5}{*}{$\begin{array}{l}\text { No field } \\
\text { collected } \\
\text { data of } \\
\text { same date }\end{array}$} \\
\hline Lat: $32^{\circ} 21^{\prime} 22^{\prime \prime} \mathrm{N}$ & Band 3 & 89.213 & 71.935 & 79.288 & 78.915 & \\
\hline Long: $77^{\circ} 07^{\prime} 38^{\prime \prime} \mathrm{E}$ & Band 4 & 84.049 & 67.772 & 74.757 & 74.330 & \\
\hline Altitude: $2851 \mathrm{~m}$ & Band 5 & 6.047 & 4.876 & 5.395 & 5.347 & \\
\hline $\begin{array}{l}\text { Slope: } 20^{\circ} \\
\text { Aspect: } 135^{\circ}\end{array}$ & NDSI & 0.871 & 0.871 & 0.871 & 0.871 & \\
\hline
\end{tabular}

Table 6. Snow cover analysis in \%, using different index techniques.

\begin{tabular}{lcccc}
\hline Date of pass & $\begin{array}{c}\text { NDSI } \\
\text { (DN values) }\end{array}$ & $\begin{array}{c}\text { NDSI } \\
\text { (planetary reflectance) }\end{array}$ & $\begin{array}{c}\text { NDSI (topographic } \\
\text { cosine correction) }\end{array}$ & $\begin{array}{c}\text { S3 } \\
\text { index }\end{array}$ \\
\hline 2 December 2004 & 78.64 & 88.54 & 88.51 & 83.46 \\
19 January 2005 & 88.69 & 94.84 & 94.84 & 91.73 \\
26 February 2005 & 96.39 & 98.77 & 98.78 & 97.98 \\
13 March 2005 & 87.02 & 90.72 & 90.66 & 89.10 \\
30 April 2005 & 49.94 & 56.83 & 56.77 & 57.47 \\
\hline
\end{tabular}

corrections) and S3 index (table 6). It was observed from table 6 that more snow cover area was estimated when reflectances were used to calculate the NDSI, instead of DN values. The ground observed data also indicated that larger amount of snow cover was more accurate. Hall et al (1995) also found that DN based NDSI underestimate the snow cover area and thus reflectance values were used to estimate NDSI. Equal snow cover areas were calculated, when NDSI was calculated using planetary reflectance (without topographic correction) and with topographic cosine correction. This shows that NDSI is independent of topographic corrections (also observed using ground measurements, i.e., table 5) and hence NDSI without topographic correction was considered for snow cover distribution in Beas basin for the year 2004-05.
Again, almost equal area of snow cover were calculated using S3 index verses when planetary reflectance values were used to calculate the NDSI, except for 2 December 2004 (table 6). This is because more snow free pixels were estimated in vegetation area using S3 than NDSI index. From the ground data it was observed that $42 \mathrm{~cm}$ fresh snowfall occurred on 30 November 2004 , which can be visually observed on satellite data up to lower elevations, therefore snow may be considered at higher elevations under forest, hence in the present study NDSI calculated from reflectance values was considered for snow cover mapping.

Secondly, it was discussed by Shimamura et al (2006), that S3 index can distinguish snow covered areas from mixels of snow and vegetation without any reference data, using the threshold value 


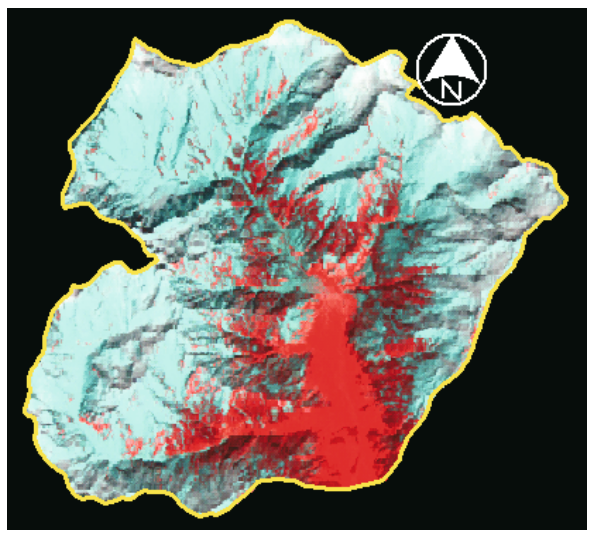

(a)

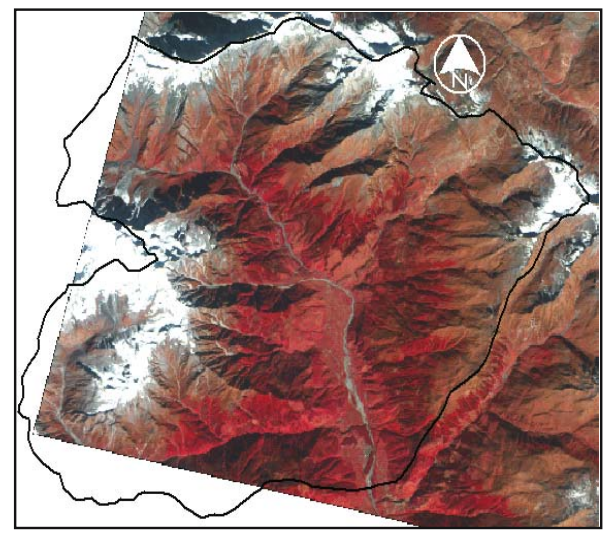

(c)

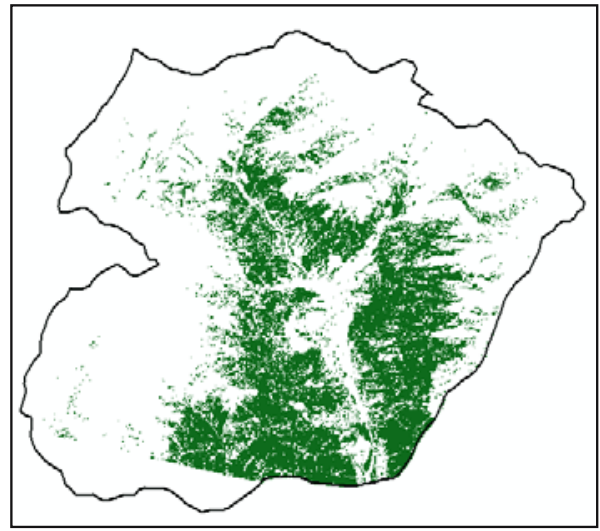

(e)

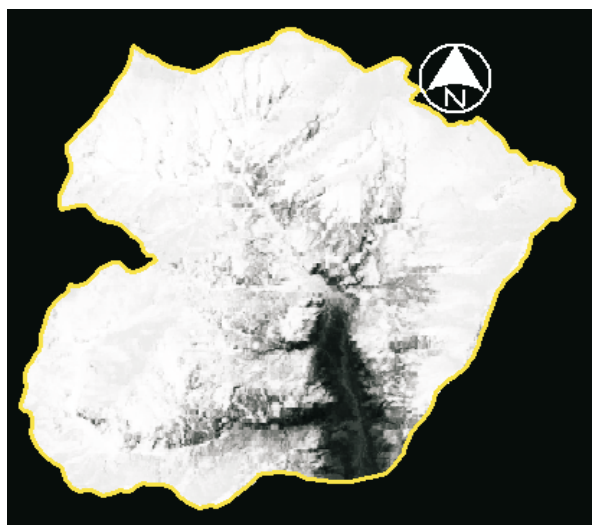

(b)

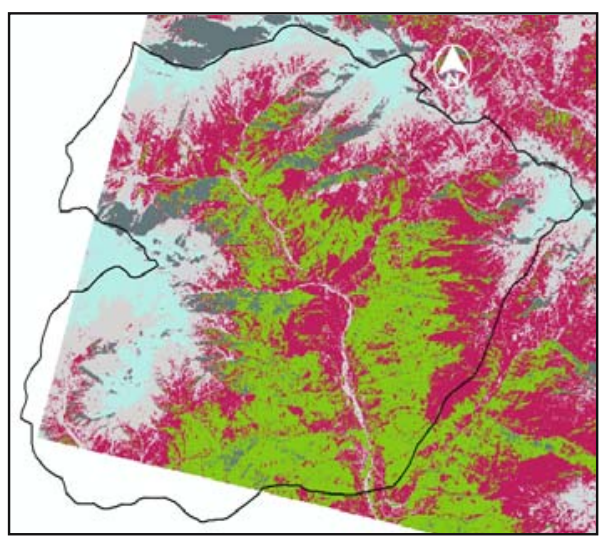

(d)

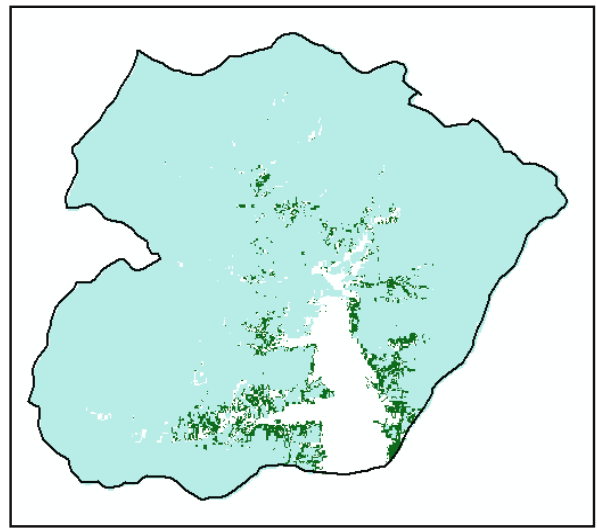

(f)

Figure 5. (a) AWiFS imagery showing the study area Beas basin (B2:B3:B5); (b) NDSI imagery; (c) LISS-IV imagery; (d) supervised classified imagery; (e) vegetation map; and (f) binary snow cover area map of the study area.

of S3 between 0.05 and 0.18 , but it was observed by applying these thresholds on satellite data for Himalayan region that the patchy and contaminated snow also lie within this threshold value. Therefore one has to use the reference data of vegetation for snow under vegetation cover. In the present study the methodology proposed in section 4.2.2 using NDSI together with vegetation information is used for the snow cover under vegetation.

\subsubsection{Snow cover distribution in Beas basin using AWiFS data}

All the 19 AWiFS scenes were pre-processed (ortho-rectified), planetary reflectance was estimated and subset of the study area were generated (figure 5a). The NDSI images were generated using reflectance images (figure 5b) and snow cover area was estimated with NDSI threshold value $\geq 0.4$ and $\mathrm{B} 4$ (NIR) reflectance $>11 \%$. The high 


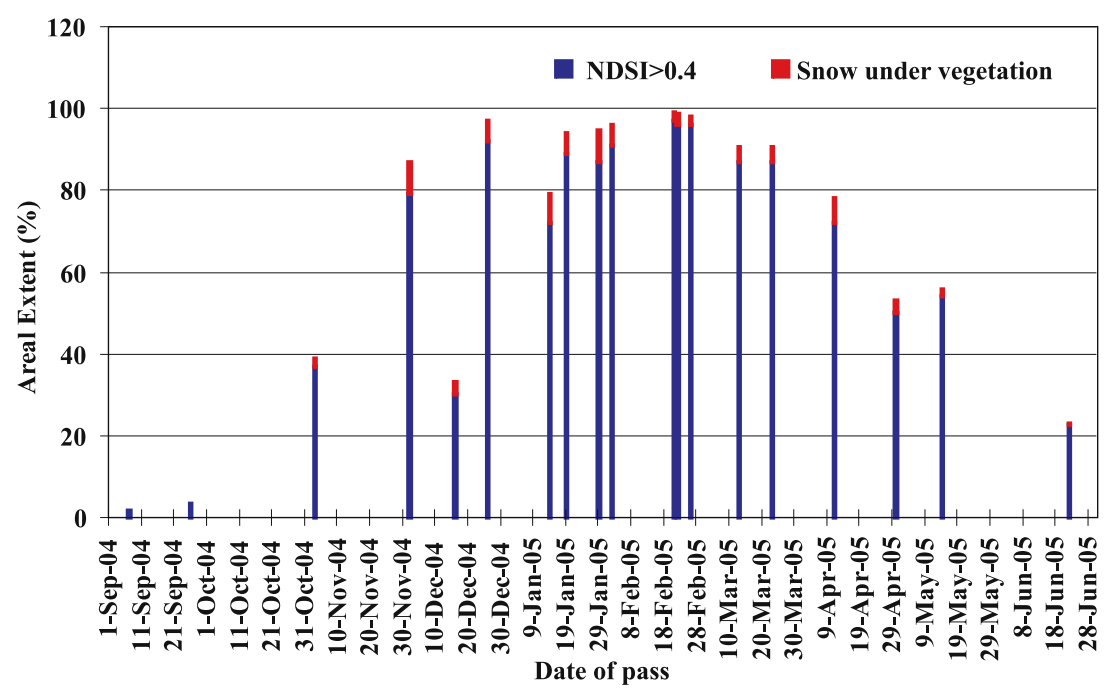

Figure 6. Snow cover distribution in Beas basin for year 2004-05.

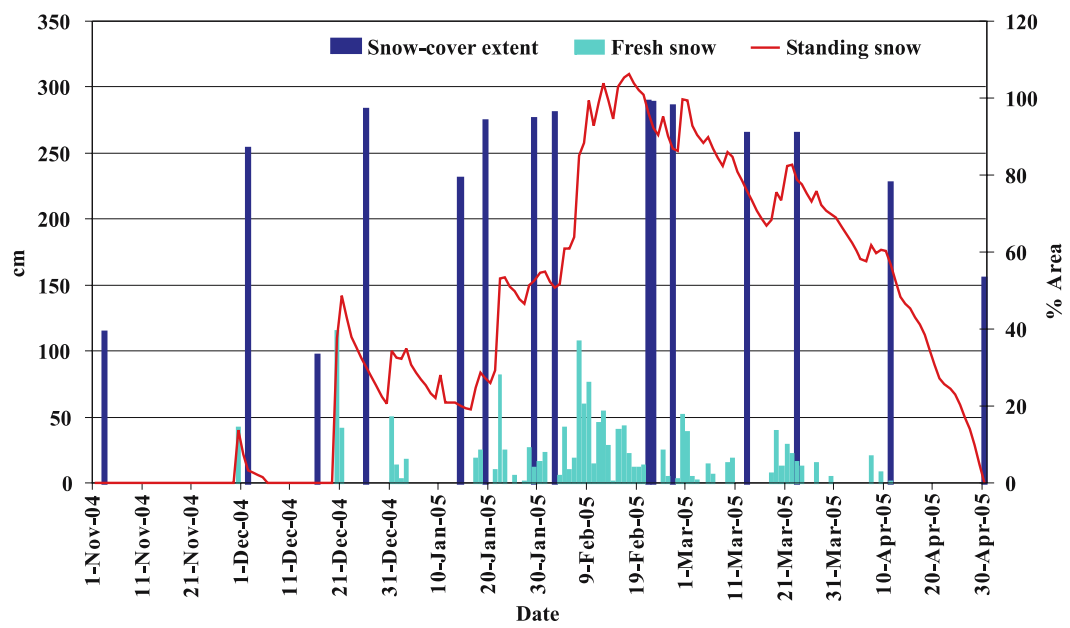

Figure 7. Ground observed snowfall and standing snow data at Dhundi Observatory and estimated snow cover area (1 November 2004 to 30 April 2005).

resolution LISS-IV (IRS-P6) multispectral imagery of pre-winter, used for mapping of vegetation is shown by figure $5(\mathrm{c})$. The classified LISS-IV imagery with five classes', viz., forest (green), snow (cyan), grassy surface (brown), soil/rocky area (thistle) and shadow (grey), is shown in figure 5(d). The error matrix of the supervised classification was generated and Kappa coefficient was found as 0.99. The total forest cover area was estimated $26 \%$ of the Beas basin area using LISS-IV data. The binary image of forested vs. non-forested area is generated (figure 5e) and also validated with IKONOS imagery of $1 \mathrm{~m}$ spatial resolution. With the help of NDSI and binary vegetation image the snow cover area under vegetation/forest was also estimated, and the total snow cover area thematic map was generated (figure $5 \mathrm{f}$ ). The map shows the snow under vegetation area (green) very less in comparison to the area of total vegetation, this may be because NDSI $\geq 0.4$ can map the pixel as pure snow pixel if fresh snow is on the top of vegetation canopy or in case of sparse forest if a pixel is even $25 \%$ of snow and $75 \%$ vegetation. Thus, the areal extent of snow cover using NDSI $\geq 0.4$ with NIR band reflectance to mask water bodies and snow under vegetation were estimated from all the AWiFS scenes and plotted in figure 6 .

The snow cover distribution pattern shows that, the seasonal snow cover start building up from November first week and undergoes a lot of variations in areal extent as winter progress (figure 6). The nature of these variations divides the winter into: early winter (November-December) with more variation in snow cover extent, peak winter 
(January-February) with less variations in snow cover extent and late winter (March-April) start reducing the snow cover extent (figure 6 ). The permanent snow field of approximate area $2-3 \%$ can be observed before winter starts.

The snow or non-snow pixel information was validated with the snow cover information collected from three observatory locations. Total 57 points were used in this exercise, out of which the algorithm fairly classified 54 points as snow or nonsnow pixels by having NDSI $\geq 0.4$ or $<0$ respectively and matches with ground information. One point on 14 January 2005, due to small cloud cover over Dhundi Observatory could not be classified. For rest, two points of Bhang Observatory, the NDSI was $\geq 0.1$ and $<0.4$, this may be because of patchy or contaminated or vegetation mixed snow. By further analysis it was found that at that location/pixel, no vegetation was present, which ignore the possibility of vegetation mixed area. By observing the reflectance data of that pixel and some pure pixel of nearby area it has been observed that the reflectance of interested pixel has decreased in first three bands and increased in the fourth band, which suggest the pixel is having patchy snow. As Negi et al (2009a) reported that in case of patchy snow the reflectance decreases in VNIR and increases in SWIR. Ground data also confirm that small snow thickness, i.e., 6 and $2 \mathrm{~cm}$ on 26 December 2004 and 19 January 2005 respectively were observed at those points. Thus the study classified all the sampled points correctly, once it was cloud free.

The increase and decrease in areal extent of snow cover was also validated with ground observed fresh snowfall and standing snow data (figure 7 ). It can be well observed from plot that as the standing snow at observatory location increases or decreases, the areal extent of snow cover also increases or decreases simultaneously. This also validates the seasonal snow cover mapping algorithm.

\section{Conclusions}

In this paper, a technique based on NDSI with vegetation information and NIR band reflectance is used for snow cover distribution in the Beas basin, which consists rugged terrain, snow under forest, contaminated snow and patchy snow. The significant variations were observed between satellite estimated reflectances and field observed reflectances using spectroradiometer due to topographic conditions, however, no variations were observed in the estimated NDSI values. Different methods based upon snow indices were attempted to find suitable index for mapping of snow cover and NDSI estimated using planetary reflectance was found the suitable index method. The estimated snow or non-snow pixel information using proposed algorithm was validated with the snow cover information collected from field locations and found that the algorithm classified all the sample points correctly, once that pixel is cloud free. A good correlation was observed between increase/decrease areal extent of seasonal snow cover and ground observed fresh snowfall and standing snow data. Considering the advantages of the AWiFS satellite sensor, similar technique will help in the estimation of seasonal snow cover for the entire lower Himalyan zone, where the vegetation cover and patchy/contaminated snow exist.

\section{Acknowledgements}

The authors are grateful to the Director, Snow \& Avalanche Study Establishment (SASE) for providing facilities to carry out this study and constant motivation during the investigation.

\section{References}

Analytical Spectral Devices 1999 Fieldspec TM, Technical Guide, 3rd edn. (Boulder, Co) USA.

Chavez P S Jr 1988 An improved dark-object subtraction technique for atmospheric scattering correction of multispectral data; Remote Sensing of Environment 24 459-479.

Chavez P S Jr 1989 Radiometric calibration of Landsat Thematic Mapper multispectral images; Photogrammetric Engineering of Remote Sensing 55 1285-1294.

Dozier J F 1984 Snow reflectance from Landsat-4 Thematic mapper. IEEE Transactions on geosciences and remote sensing 22(3) 323-328.

Dozier J 1989 Spectral signature of alpine snow cover from the Landsat Thematic Mapper; Remote Sens. Environ. 28 9-22.

Dozier J, Schneider S R and Mcginnis Jr D F 1981 Effect of grain size and snow pack water equivalent on visible and near infrared satellite observations of snow; Water Resour. Res. 17(4) 1213-1221.

Ekstrand S 1996 Landsat TM-Based Forest Damage Assessment: Correction for Topographic Effects; PE\&RS 62(2) $151-161$

Gupta R P, Haritashya U K and Singh P 2005 Mapping dry/wet snow cover in the Indian Himalayas using IRS multispectral imagery; Remote Sens. Environ. 97 458-469.

Hall D K, Riggs G A and Salomonson V V 1995 Development of methods for mapping global snow cover using moderate resolution imaging spectroradiometer data; Remote Sens. Environ. 54 127-140.

Hall D K, Foster J L, Verbyla D L, Klein A G and Benson C S 1998 Assessment of snow-cover mapping accuracy in a variety of vegetation-cover densities in central Alaska; Remote Sens. Environ. 66 129-137.

Hall D K, Riggs G A, Salomonson V V, DiGirolamo N and Bayr K J 2002 MODIS snow cover products; Remote Sens. Environ. 83 181-194. 
Kasten F 1962 Table of solar altitudes for geographical latitudes $\pm 77^{\circ} 10^{\prime}$; CRREL Special Report 57 U.S. Army Corps of Engineers, Hanover, New Hampshire.

Klein A G, Hall D K and Riggs G A 1998 Improving snow cover mapping in forests through the use of a canopy reflectance model; Hydrol. Proc. 12 1723-1744.

Konig M, Winther J G and Isaksson E 2001 Measuring snow and glacier properties from satellite; Rev. Geophys. 39 $1-27$.

Kulkarni A V, Mathur P, Rathore B P, Suja Alex, Thakur N and Manoj 2002a Effect of global warming on snow ablation pattern in the Himalaya; Curr. Sci. 83 120-123.

Kulkarni A V, Srinivasulu J, Manjul S S and Mathur P 2002b Field based spectral reflectance to develop NDSI method for the snow cover; J. Indian Soc. Remote Sens. 30(1\&2) 73-80.

Kulkarni A V and Rathore B P 2003 Snow cover monitoring in baspa basin using IRS WiFS data; Mausam 54 335-340.

Kulkarni A V, Singh S K, Mathur P and Mishra V D 2006 Algorithm to monitor snow cover using AWiFS data of RESOURCESAT-1 for the Himalayan region; Int. J. Remote Sens. 27(12) 2449-2457.

Markham B L and Barker J L 1986 Landsat MSS and TM post-calibration Dynamic ranges, exoatmospheric reflectances and at-satellite temperature; EOSAT Technical Notes $13-8$.

Meyer P, Itten K I, Kellenberger J, Sandmeier S and Sammeier R 1993 Radiometric correction of topographically induced effects on Landsat TM data in an alpine environment; ISPRS Journal of Photogrammetry and Remote Sensing 48 17-28.

Minnaert M 1941 The reciprocity principle in lunar photometry; Astrophys. J. 93 403-410.

Moran M S, Jackson R D, Slater P N and Teillet P M 1992 Evaluation of simplified procedures for retrieval of land surface reflectance factors from satellite sensor output; Remote Sens. Environ. 41 169-184.

Negi H S, Snehmani and Thakur N K 2008 Operational Snow Cover Monitoring in NW-Himalaya using Terra and Aqua MODIS Imageries; Proceedings International Workshop on Snow, Ice, Glacier and Avalanches, IIT Mumbai, India, 7-9 January, 11-25.

Negi H S, Kulkarni A V and Semwal B S 2009a Study of Contaminated and Mixed Objects Snow Reflectance in Indian Himalaya using Spectroradiometer; Int. J. Remote Sens. 30(2) 315-325.

Negi H S, Singh S K, Kulkarni A V and Semwal B S 2009b Field Based Spectral Reflectance Measurements of
Seasonal Snow Cover in Indian Himalaya; Int. J. Remote Sens., in press.

Rango A and Martinec J 1982 Snow accumulation derived from modified depletion curves of snow coverage; Symposium on Hydrological Aspects of Alpine and High Mountain Areas, IAHS Publication No. 138 83-90.

Robinson D A and Kukla G 1985 Maximum surface albedo of seasonally snow covered lands in the northern Hemisphere; J. Climate and Applied Meteorology 24 $402-411$

Saito A and Yamazaki T 1999 Characteristics of spectral reflectance for vegetation ground surfaces will snowcover: Vegetation indices and snow indices; J. Japan Soc. Hydrol. Water Res. 12 28-38.

Sharma S S and Ganju A 2000 Complexities of avalanche forecasting in Western Himalaya - An overview; Cold Regions Science and Technology 31 95-102.

Shimamura Y, Izumi T and Matsuyama H 2006 Evaluation of a useful method to identify snow-covered areas under vegetation - comparisons among a newly proposed snow index, normalized difference snow index, and visible reflectance; Int. J. Remote Sens. 27(21-22) 4867-4884.

Singh D and Ganju A 2006 Improvement in nearest neighbour weather forecast model performance while considering the previous day's forecast for drawing forecast for the following day; Curr. Sci. 91(12) 1686-1691.

Slater P N 1980 Remote sensing optics and optical systems, Addison-Wesley Publishing Company Inc. Massachusetts, USA.

Smith J A, Tzeu L L and Ranson K J 1980 The lambertian assumption and Landsat data; PEESRS 46(9) 1183-1189.

Song C, Woodcock C E, Seto K C, Lenney M P and Macomber A S 2001 Classification and change detection using Landsat TM data: When and how to correct atmospheric effects; Remote Sens. Environ. 75 230-244.

Teillet P M, Guindon B and Goodenough D G 1982 On the slope aspect correction of multispectral scanner data; Canadian J. Remote Sens. 8(2) 84-106.

Townshend J R G and Tucker C J 1984 Objective assessment of advanced very high resolution radiometer data for land cover mapping; Int. J. Remote Sens. 5 497-504.

Tucker C J 1979 Red and photographic infrared linear combinations for monitoring vegetation; Remote Sens. Environ. 8 127-150.

Tucker C J 1986 Maximum normalized difference vegetation index images for sub-Saharan Africa for 1983-1985; Int. J. Remote Sens. 7 1383-1384.

Xiao X, Shen Z and Qin X 2001 Assessing the potential of VEGETATION sensor data for mapping snow and ice cover: A normalized difference snow and ice index; Int. J. Remote Sens. 22 2479-2487. 